\title{
Decisões judiciais em matéria de saúde: as conexões entre o Direito e a Moral
}

Judicial decisions on health: the connections between law and morals

Decisiones de los tribunales sobre la salud: las conexiones entre Derecho y Moral

José Carlos Zebulum ${ }^{1}$

\begin{abstract}
RESUMO: A partir da transferência, cada vez mais intensa, da atribuição de decidir questões importantes na área da saúde, para o Judiciário, justifica-se o interesse em investigar, identificar e compreender os principais conflitos morais experimentados por magistrados no cotidiano de sua jurisdição de saúde, buscando compreender as razões desses conflitos e o modo pelo qual têm sido deliberadas questões de saúde em face dos entes públicos. Uma vez que nestas situações, os juízes, de uma forma geral, dispõem de certa margem de liberdade na escolha dos padrões - políticas, princípios (jurídicos ou morais) ou regras - que devem utilizar, em alguns casos, para chegar a uma decisão que considerem adequada, avulta-se a questão do chamado poder discricionário do juiz. Mas até onde vai a discricionariedade dos juízes? Será que podem decidir livremente, de acordo com as regras jurídicas, princípios jurídicos, política, ou mesmo de acordo com suas convicções morais, a seu único e exclusivo talante? Este estudo busca trazer respostas para estas questões a partir da teoria de Ronald Dworkin, no contexto de suas divergências com Herbert L. A. Hart e Richard Posner, mais especificamente no que diz respeito às conexões entre a moral e o direito. Ao final, desenvolvemos uma técnica a fim de identificar conflitos morais experimentados pelos magistrados que aplicamos em casos concretos de demandas de saúde.
\end{abstract}

Palavras-chave: Direito à Saúde. Judicialização. Princípios Morais.

ABSTRACT: The importance of investigating, identifying and understanding the main moral conflicts experienced by magistrates in the daily life of their health jurisdiction is justified from the increasingly intense transfer of the decision on important issues in the area of health to the Judiciary. Given that in these situations, judges generally have a margin of discretion in choosing standards - policies, principles (legal or moral) or rules - that they should use in some cases to obtain an adequate result, the question of the so-called discretionary power of the judge is highlighted. But how far goes the discretion of the judges? Can they freely decide, according to legal rules, legal principles, politics, or even according to their moral convictions, in their unique and exclusive mind? This study seeks to bring answers to these questions from Ronald Dworkin's theory, in the context of their differences with Herbert L. Hart and Richard Posner, specifically with regard to the connections between morality and law. In the end, we developed a technique to identify moral conflicts experienced by magistrates that we apply in concrete cases of health demands.

\footnotetext{
1 Bacharel em Direito pela Universidade do Estado do Rio de Janeiro (UERJ). Mestre em Direito Civil Universidade do Estado do Rio de Janeiro (UERJ). Doutorando em saúde coletiva pelo Instituto de Estudos de Saúde Coletiva da Universidade Federal do Rio de Janeiro (UFRJ). Juiz Federal no Estado do Rio de Janeiro. Email: jcarloszebulum@gmail.com
} 
Keywords: Right to Health. Judicialization. Moral principles.

RESUMEN: Desde la integración, cada vez más intensa, la asignación para decidir cuestiones importantes en materia de salud, al poder judicial, el interés justifica investigar, identificar y comprender los principales conflictos morales experimentados por los magistrados en su jurisdicción diario de la salud, tratando de comprender las razones de estos conflictos y la manera que tienen problemas de salud se han resuelto en la cara de las entidades públicas. Desde estas situaciones, los jueces, en general, tienen un cierto grado de libertad en la elección de las normas - políticas, principios (legales o morales) o reglas que debe utilizar, en algunos casos, para llegar a una decisión considere apropiado, los telares de la cuestión del llamado criterio del juez. Pero ¿hasta dónde va a discreción de los jueces? ¿Pueden decidir libremente, de acuerdo con las normas legales, principios legales, políticas, o incluso de acuerdo a sus costumbres, su talante único y exclusivo? Este estudio busca proporcionar respuestas a estas preguntas de la teoría de Ronald Dworkin en el contexto de sus diferencias con Herbert L. A. Hart y Richard Posner, específicamente con respecto a las conexiones entre la moral y el derecho. Al final, hemos desarrollado una técnica para detectar los conflictos morales que experimentan los magistrados que aplican en los casos concretos de las demandas de salud.

Palabras-Ilave: Derecho a la Salud. Judicialización. Principios morales.

\section{Introdução}

Há milênios convivemos com uma concepção de justiça ideal na medicina, influenciada por René Descartes, pela qual a vida e a saúde são os bens mais importantes, enquanto que todos os demais bens são de menor importância e devem ser sacrificados em favor destes dois. Consequentemente, louvamos a ideia de que a assistência médica deve ser prestada a qualquer um que dela necessite, e não admitimos que alguém seja privado da devida assistência simplesmente porque não pode custeá-la. Afinal, uma vida digna pressupõe o afastamento da dor e da doença, ao menos enquanto isto estiver ao alcance da medicina (1).

No entanto, uma vez que os recursos financeiros são escassos e insuficientes para o atendimento de todas as necessidades sociais, inclusive aquelas relacionadas à saúde, a formulação das políticas sociais e econômicas voltadas à implementação deste direito fundamental implicará, necessariamente, em escolhas alocativas ${ }^{2}$, escolhas estas que devem se orientadas por critérios de justiça distributiva (o quanto disponibilizar, a quem

\footnotetext{
${ }^{2}$ A necessidade de se impor um racionamento à assistência médica (ao menos nos países que adotaram sistemas de saúde patrocinados, no todo ou em parte, pelo ente público) se avulta na medida em que a ciência médica vem descobrindo medicamentos e tratamentos cada vez mais caros, tornando os gastos com assistência médica cada vez mais significativos. Atualmente, não se paga mais pela mesma assistência médica pela qual se pagava menos anteriormente; pelo contrário, paga-se mais por uma assistência que disponibiliza uma variedade muito maior de tratamentos e medicamentos (1).
} 
atender e a quem não atender), configurando-se como típicas opções políticas, que pressupõem "escolhas trágicas"(2). Trata-se de escolhas a serem feitas, em princípio, pelo Poder Executivo, uma que este, dispondo das informações necessárias para analisar as consequências globais da destinação de recursos públicos, está, de fato, em melhores condições de tomar decisões neste sentido.

No Brasil, a simples atribuição constitucional aos entes federados, de diversas responsabilidades na área da saúde (3), além da legislação subjacente (4), (5), não foram suficientes para solucionar as dificuldades que a população brasileira já vinha enfrentando para ter concretizado, na prática, o direito fundamental. Desta feita, as pessoas passam a procurar, através da via judicial, obter a assistência à saúde que, ao menos em boa parte dos casos, deveria estar sendo prestada diretamente nos hospitais e demais órgãos públicos. Este fenômeno é conhecido como "judicialização da saúde", que compreende, portanto, a provocação do Poder Judiciário em prol da efetivação da assistência médica e/ou farmacêutica. Diante de determinações proferidas judicialmente, a Administração passa a ser constrangida a prestar atendimento médico e assistência farmacêutica, o que produz repercussões tanto na política de saúde como sobre os cofres públicos (6), o que vem fazendo com que diversas críticas sejam dirigidas ao Poder Judiciário e, em particular, aos juízes. ${ }^{3}$

Transfere-se, assim, uma atividade própria e inerente ao Estado-administração para o Estado-juiz, qual seja, a de tomar decisões na área da saúde, mais especificamente no que diz respeito ao fornecimento de medicamentos e tratamentos gratuitos àqueles que os demandam. Exige-se, portanto, que o Poder Judiciário assuma com eficiência este papel, realizando, aqui a justiça em sua perspectiva distributiva, e conferindo ares de concretude ao direito fundamental. Assim, diante da relevância do papel assumido pelos juízes neste mister, justifica-se o interesse em investigar, identificar e compreender os principais conflitos morais experimentados por magistrados no cotidiano de sua jurisdição de saúde, buscando compreender as razões desses conflitos e o modo pelo qual têm sido deliberadas questões de saúde em face dos entes públicos, e considerando-se as leis, a jurisprudência e as

\footnotetext{
${ }^{3}$ A interferência do Poder Judiciário em tarefa que, a princípio, seria da atribuição do Poder Executivo, aliada ao crescimento exponencial do número de ações judiciais propostas em face do Poder Público com o fim de garantir o fornecimento de medicamentos, a realização de cirurgias e procedimentos, e a incorporação de novas tecnologias no âmbito do SUS (7), vêm suscitando intensos debates na seara doutrinária e jurisprudencial. Transfere-se, assim, para os juízes, a responsabilidade de tomar decisões em questões ligadas a saúde das pessoas.
} 
políticas de saúde pública no âmbito da assistência à saúde individual. De acordo com Freitag (6), os chamados conflitos morais podem ser entendidos como situações em que dois ou mais interesses legítimos estão em conflito e não podem ser dirimidos, a priori, sem que haja a necessária ponderação dos interesses envolvidos.

\section{Os conflitos morais experimentados pelos juízes no exercício da jurisdição em saúde.}

É importante salientar que em diversas situações - aqui considerados apenas os casos de tutela individual -, por ocasião do julgamento de demandas judiciais de saúde, os juízes se defrontam com os chamados casos difíceis, assim designados pela teoria do positivismo jurídico de Herbert L. A. Hart, que não são normalmente resolvidos pela subsunção direta a uma regra jurídica estabelecida de forma explícita pela instituição competente. Nestes casos, o magistrado será levado a exercer a sua discricionariedade, aventando a possibilidade de decidi-los com base em outros padrões, tais como os princípios, a política ou suas próprias convicções morais, experimentando, assim, os chamados conflitos morais acima definidos (6). Podemos, desde já, identificar algumas situações retiradas, a título de exemplo, de casos concretos na área da saúde, que bem denotam a relevância e a pertinência desta abordagem:

1. Submete-se à apreciação do juiz pedido de fornecimento de medicamento ou tratamento que causará um grande impacto no orçamento do ente público envolvido.

2. Submete-se à apreciação do juiz, com justificativa de urgência lastreada em laudo médico, pedido liminar de fornecimento de prestação de saúde não registrada na Agência Nacional de Vigilância Sanitária (ANVISA), fora dos casos excepcionalmente admitidos na legislação. ${ }^{4}$

\footnotetext{
${ }^{4}$ Outros casos ainda podem ser lembrados, tais como: (1) submete-se à apreciação do juiz, com justificativa de urgência lastreada em laudo médico, pedido liminar de fornecimento de prestação de saúde cujo procedimento não consta da tabela de procedimentos do SUS, nem está previsto em Protocolos Clínicos e Diretrizes Terapêuticas do SUS; (2) em demanda para fornecimento de prestação de saúde, o juiz, em função do que determinam as regras de natureza processual, se vê obrigado a declinar de sua competência para outro foro, o que provocará retardamento incompatível com a urgência comprovada nos autos; (3) em que pese a determinação legal para realização de audiência de conciliação e mediação, a parte autora, diante da postura reiterada dos advogados públicos em se recusar terminantemente a qualquer tentativa de conciliação, requer ao magistrado que a audiência não seja designada; (4) usuário que se encontra em fila de espera para tratamento médico-cirúrgico em hospital público, mediante justificativa de comprovado o agravamento em seu quadro clínico, busca o provimento jurisdicional para obter prioridade de atendimento em relação aos demais; (5) o juiz verifica que a lei, ou os entendimentos jurisprudenciais que orientam a resolução do feito, se revelam anacrônicos; (6) submete-se à apreciação do juiz pedido de fornecimento de medicamento ou tratamento de saúde de alto custo, que implicaria em grave lesão às finanças pública, a usuário terminal, sem chance de cura, apenas para aumentar a sobrevida; (7) usuário, com
} 
Impõe-se, portanto, uma abordagem teórica mais aprofundada a respeito dos chamados "casos difíceis", para que possamos evoluir em nosso estudo.

\section{Dworkin e o positivismo jurídico de Hart: os chamados "casos difíceis".}

Segundo a teoria que Ronald Dworkin denomina de "positivismo jurídico", o direito de uma comunidade é caracterizado por um conjunto de regras especiais ${ }^{5}$ que irão definir os comportamentos que serão autorizados e os comportamentos que serão, eventualmente, coagidos, e até mesmo punidos pelo Poder Público. Assim, as obrigações jurídicas e os direitos que podem ser atribuídos a cada um dependem do enquadramento do caso específico em uma regra jurídica válida (7). O autor assinala a existência de diferentes versões do positivismo, mas considera mais completa a versão de Herbert L.A. Hart ${ }^{6}$, que distingue dois tipos de regras, as "primárias" e as "secundárias". As regras primárias seriam aquelas que concedem direitos ou impõem obrigações aos membros da comunidade, enquanto que as regras secundárias seriam aquelas que estabelecem como e por quem tais regras podem ser estabelecidas, modificadas ou revogadas. Assim, se alguém está submetido a uma regra primária, está obrigado a fazer o que ela determina (ou a não realizar a conduta que ela proíbe), sob pena de sofrer uma sanção que a própria regra estabelece, daí evidenciando-se a sua normatividade, que decorre, justamente, do fato ter sido editada respeitando-se as diretrizes fixadas nas regras secundárias acima referidas.

Assim, o conjunto destas regras jurídicas que conformam o "direito" deve, em princípio, oferecer respostas às diversas questões que possam ser apresentadas pela comunidade, de modo que, se o caso de alguma pessoa não estiver claramente coberto por alguma

elevado nível de renda familiar, requer, judicialmente, fornecimento de determinada prestação de saúde pelo SUS; (8) diante de pedido para fornecimento de determinado tratamento, o NATs informa ao juiz que há pouca literatura sobre o tema, com resultados imprecisos e alguns mostrando, inclusive, que essa prática pode piorar o quadro clínico do usuário; (9) usuário idoso, com quadro clínico grave, já internado em hospital da rede privada, requer transferência, com urgência, a hospital público especializado, onde poderá receber melhor atendimento. Ocorre que, segundo o laudo médico, a transferência coloca em risco a sua vida; (10) a parte autora requer concessão de antecipação da tutela, no sentido de que Ihe seja assegurado o direito ao fornecimento de determinado medicamento conforme prescrição médica. O juiz designa a realização de perícia, mas o autor não comparece, argumentando dificuldades de deslocamento. A advocacia pública requer a extinção do feito sem resolução do mérito, caracterizada a ausência de interesse processual.

${ }_{5}$ Manuel Atienza, observa, no entanto, que o direito é um fenômeno complexo e que pode ser visto sob diferentes perspectivas. Na primeira, que pode ser chamada de estrutural, o direito é composto essencialmente por um conjunto de normas jurídicas. Em uma segunda abordagem, o direito é estudado sob um ponto de vista funcional, que tende a se identificar com a conduta de juízes e dos demais operadores, uma vez que, sob este ponto de vista, o que importa não é o direito formalmente válido (aquele que se revela através dos livros e das normas jurídicas), mas o direito em ação, o direito verdadeiramente eficaz - esta perspectiva é, sem dúvida, a que nos interessa com maior ênfase neste trabalho. Finalmente, a partir de um terceiro ponto de vista, o direito se confunde com o ideal de justiça, ou seja, o direito exemplar, aquele que tem, de fato, aptidão para distribuir ou realizar a justiça (8).

${ }^{6}$ Vide. Hart, HLA. The Concept of Law, p. 89-96, 1961. 
dessas regras (porque não existe nenhuma que pareça apropriada ou porque as que parecem apropriadas são vagas, ou por outra razão), então esse caso não pode ser resolvido pela simples "aplicação do direito"7. Teríamos, assim, os chamados hard cases, que se diferenciariam dos casos simples pelo fato destes últimos admitirem uma solução que decorreria da mera adequação, da simples subsunção do fato concreto à lei previamente estabelecida, enquanto que os primeiros exigiriam do intérprete uma atividade mais complexa no momento de decidir, com maiores construções hermenêuticas.

Antes de prosseguirmos, é importante assinalarmos, porém, a existência de críticas doutrinárias a esta divisão estrutural entre casos fáceis e difíceis, que refletiria uma classificação equivocada e arbitrária, uma vez que para se estabelecer a diferença entre os dois casos, já se recorre à própria compreensão do que seria um caso difícil, estabelecendose um ciclo sem fim. Adverte-se que a partir dessa classificação equivocada, surgiu, como corolário, um segundo erro, em que os casos fáceis seriam resolvidos por mera subsunção da situação concreta à legislação em vigor, enquanto que, na outra ponta, os casos difíceis estariam a exigir do julgador uma atividade mais complexa, que consistiria em percorrer "uma trilha discursiva-argumentativa" que pudesse apresentar resposta adequada à questão (9).

Lenio Streck também enfatiza a questão observando que a construção de racionalidades discursivas acabou substituindo a razão prática, questão bem presente nas diversas teorias da argumentação. Segundo o autor, isso fez com que a questão da interpretação fosse alçada ao patamar da argumentação, a partir da construção de racionalidades comunicativas, estabelecendo, previamente, modos de operar diante da indeterminabilidade do direito. No entanto, prossegue, a teoria da argumentação paradoxalmente cria um problema de difícil solução se entendermos que hard e easy cases têm um sentido próprio, já que deliberar se tal caso é fácil ou difícil (para aplicar subsunções ou não) já constitui, em si mesmo, um precedente easy-hard case. O que levaria, de modo regressivo, ao infinito (10). Segundo o autor, Dworkin não cinde os casos simples dos casos difíceis, apenas os separa, diferentemente de outros que pretendem estabelecer, com esta

\footnotetext{
${ }^{7}$ Em verdade, a decisão a ser prolatada reflete o ato final de um processo decisório, que se inicia com o conhecimento dos fatos e a interpretação da lei. A palavra "interpretação" tem sentido próprio no âmbito jurídico, e diz respeito à atividade de busca, empreendida pelo magistrado - ou outro intérprete -, do verdadeiro alcance e significado da norma. Assim, enquanto "interpretar" quer dizer uma atividade, hermenêutica tem sentido distinto, uma vez que nos remete a uma ciência, a ciência que se dedica ao estudo das diversas técnicas de interpretação. Após interpretada, a lei deve ser aplicada, etapa final do processo, quando então, após a subsunção da norma ao caso concreto o juiz estará decidindo a questão.
} 
classificação, uma cisão na compreensão e interpretação, tornando arbitrária a atribuição de sentido ao que seja um caso fácil ou um caso difícil (10). Lenio Streck (10) reitera:

Distinguir casos simples de casos difíceis não é o mesmo que cindir casos simples de casos difíceis. Essa pode ser a diferença entre a dicotomia hard e easy cases de Dworkin e das teorias discursivo-procedurais. Cindir hard cases e easy cases é cindir o que não pode ser cindido: o compreender, com - qual sempre operamos, que é condição de possibilidade para a interpretação (portanto, de atribuição de sentido do que seja um caso simples ou um caso complexo). Afinal, como saber se estamos em face de um caso simples ou de um caso difícil? Já não seria um caso difícil decidir se um caso é fácil ou difícil?

Não haveria, portanto, uma essência autoexplicativa do que seriam os casos fáceis e difíceis, como também não seria possível estabelecer uma divisão lógico-matemática entre as duas espécies de casos. A identificação desse marco divisório exigiria muito mais do que uma mera pré-compreensão do caso pelo intérprete. Em outras palavras, é perfeitamente possível que um dado caso seja de intrincada solução para determinado observador, e para outro intérprete o caso seja facilmente resolvido, não exigindo maiores construções hermenêuticas para o alcance do resultado final (9). Todavia, não se nega, a priori, a existência de casos difíceis, o que se rechaça é que os casos tenham intrinsecamente, em seu "código genético", a essência da sua dificuldade ou da facilidade (10).

Ainda cuidando do embate entre Hart e Dworkin, devemos registrar uma importante discordância entre os autores, eis que, segundo Hart, em qualquer sistema jurídico, podem surgir situações não cobertas pelas normas jurídicas, o que tornaria o direito lacunoso ou incompleto; logo, em tais situações, caberia ao julgador exercer seu poder discricionário ${ }^{8} \mathrm{de}$ criação de normas para dar uma solução ao feito. $O$ autor adverte, no entanto, que o poder criativo dos tribunais deve ser exercido somente diante da necessidade de ser resolver um determinado caso concreto e com parcimônia, observando limitações, já que não caberia ao juiz introduzir amplas reformas normativas (11). Por outro lado, Dworkin defende que não há incompletude no direito em si, mas sim na imagem que os positivistas (entre eles Hart) têm do direito (12). Ao não considerarem os princípios como fontes implícitas do direito, os positivistas retiram seu caráter interpretativo, que confere plenitude (e não incompletude!)

\footnotetext{
${ }^{8}$ Ainda veremos com mais atenção o que deve ser entendido por poder discricionário dos juízes.
} 
ao sistema de normas. Portanto, sob este ponto de vista, não haveria espaço para a discricionariedade judicial $(13)^{9}$.

Dworkin critica, portanto, o chamado "normativismo", que considera o direito um sistema composto exclusivamente por regras, o que impõe, necessariamente, a existência de lacunas ao ordenamento jurídico, na medida em que as normas (do padrão regra jurídica) não acompanham a dinâmica das transformações que ocorrem no seio da sociedade, e assim, inevitavelmente, surgirão situações concretas para as quais não existirá nenhuma regra jurídica apropriada. Nesta linha de orientação, salienta que a teoria dos princípios assume fundamental importância na solução dos chamados hard cases (7), que, como vimos, envolvem situações de maior complexidade que, ao serem submetidas ao Poder Judiciário, exigirão por parte do julgador um maior exercício de interpretação, reflexão e ponderação no momento de proferir sua decisão, eis que não alcançará a solução pela simples aplicação de uma regra jurídica previamente estabelecida pela instituição competente.

Portanto, enquanto Hart defende que nestes casos, em virtude de um sistema incompleto ou lacunoso, o juiz ver-se-á obrigado a exercer seu poder discricionário para chegar a uma decisão (11), Dworkin considera que mesmo nos hard cases a solução decorre do próprio ordenamento jurídico, que prevê outros padrões diferentes do padrão da regra jurídica. Assim, Dworkin preconiza que diante de um hard case, o juiz exercerá seu "discernimento pessoal" e recorrerá a outros tipos de padrão, que não a regra jurídica, que possa orientá-lo na solução do caso; padrões estes que não funcionam, exatamente, como as regras acima referidas, mas como princípios, políticas, etc (7). Impõe-se, portanto, melhor identificá-los e distingui-los, segundo a mesma doutrina, o que será feito no item que segue.

\section{Os padrões das regras jurídicas, da política e dos princípios jurídicos.}

Tomaremos como "política" aquele tipo de padrão que estabelece um objetivo a ser alcançado, em geral uma melhoria em algum aspecto econômico, político ou social da comunidade. Os argumentos de política justificam uma decisão política, mostrando que a decisão fomenta ou protege algum objetivo da comunidade como um todo. Assim, quando o juiz decide um determinado caso, adotando como justificativa a preservação do sistema de

${ }^{9}$ Como será visto no momento oportuno, Dworkin não nega a discricionariedade judicial, mas lhe impõe rigorosos limites, sob pena de restar vunerado o princípio do Estado democrático de direito. 
saúde pública, ou buscando assegurar uma melhoria no atendimento à população, adota como razão de decidir uma argumentação política ${ }^{10}$.Tomaremos como "princípio" - ou princípio jurídico - um padrão que deve ser observado, não porque vá assegurar uma situação mais interessante em termos econômicos, políticos ou sociais, mas porque é uma exigência de justiça, equidade ${ }^{11}$, ou alguma outra dimensão da moralidade. Assim, quando o juiz justifica a concessão de determinada medida terapêutica pelo Estado, com base no entendimento de que a saúde é direito de todos e dever do Estado, adota como razão de decidir um argumento de princípio.

Tais padrões diferem, ainda, do tipo que tomaremos por "regras jurídicas", que se distinguem dos princípios jurídicos quanto à natureza da orientação que oferecem. Uma regra jurídica é aplicada à maneira do tudo ou nada, isto é, se o intérprete a considera válida e apropriada ao caso, a resposta que ela fornece deve ser aceita, caso contrário, não contribuirá em nada para a solução do caso (7). O mesmo não ocorre com o princípio jurídico, que pode ser aplicado de forma ponderada com outros princípios, que podem, no caso particular, oferecer razões mais fortes para que a decisão siga uma outra orientação. Os princípios, diferentemente das regras jurídicas, não se apresentam como imperativos categóricos, determinações definitivas nem ordenações de vigência diretamente emanados do legislador. Antes, apenas enunciam motivos para que o seu aplicador se decida neste ou naquele sentido (14). Assim, ao verificar que o medicamento, cujo fornecimento a parte pretende obrigar o SUS, não se encontra registrado na ANVISA, o juiz poderá decidir a partir da simples aplicação de uma regra jurídica, no caso, de um dispositivo de Lei, que não oferecerá outra resposta que não a denegação do pedido. Da mesma forma, se um juiz de

\footnotetext{
10 Alguns juízes, no momento de decidir sobre pedidos individuais de medicamentos ou de serviços de saúde, adotam uma perspectiva ética utilitarista, pela qual não é possível se impõe restrições ao atendimento de demandas individuais, com o objetivo de se proporcionar um maior benefício para um maior número de pessoas. Assim, a eficácia do direito à saúde ficaria restrita aos serviços e insumos disponíveis do SUS, e aos limites orçamentários, ainda que haja pedido médico com objeto distinto. As críticas a este posicionamento salientam que esta perspectiva utilitarista, sempre voltada ao bem-estar geral, desconsidera as necessidades do indivíduo em si, instrumentalizando-o em função do todo.

11 Trata-se de um dos princípios doutrinários do Sistema Único de Saúde (SUS), e que deve permear o acesso às ações e aos serviços de saúde, evitando-se a manutenção de um sistema viciado por uma ótica de exclusão e perpetuação de desigualdades. Aliás, a equidade se relaciona diretamente com os conceitos de igualdade e de justiça. A adoção deste princípio impõe o atendimento aos indivíduos de acordo com suas necessidades, oferecendo mais a quem mais precisa e menos a quem requer menos cuidados. Busca-se, assim, reconhecer as diferenças nas condições de vida e saúde e nas necessidades das pessoas, considerando que o direito à saúde passa pelas diferenciações sociais e deve atender a diversidade. O princípio da equidade também norteia políticas de saúde, reconhecendo necessidades de grupos específicos e atuando para reduzir o impacto dos determinantes sociais da saúde aos quais estão submetidos. Neste sentido, no Brasil, existem programas de saúde em acordo com a pluralidade da população, contemplando as populações do campo e da floresta, negros, ciganos, pessoas em situação de rua, idosos, pessoas com deficiência, entre outros. [Acesso em 14 jun 2016]. Disponível em: http://pensesus.fiocruz.br/equidade.
} 
juizado especial declina de sua competência para julgar determinado caso, em favor de uma vara comum, porque verifica que o valor da causa supera o patamar de sessenta salários mínimos, está fundamentando sua decisão em determinada regra de direito, novamente, um dispositivo legal, de cuja aplicação não poderia resultar outra solução. Observe-se, no entanto que, no primeiro caso, o juiz, poderia, sob certas condições, decidir de forma diferente, à luz do princípio de que a saúde é um direito fundamental do ser humano, cabendo ao Estado prover as condições indispensáveis ao seu pleno exercício. Também no segundo caso, verificada a urgência, e buscando de evitar maiores danos à parte, com o retardamento que decorreria do incidente de declínio de competência, o juiz poderia afastar a incidência da regra jurídica naquele caso em particular, e considerar-se competente com base no princípio da instrumentalidade das formas do processo civil brasileiro ${ }^{12}$.

Essa primeira diferença entre regras e princípios traz consigo uma outra: os princípios possuem uma dimensão que as regras não têm, a dimensão do peso (dimension of weight) ou da importância. Quando dois ou mais princípios concorrem para a solução do feito, oferecendo respostas em diferentes orientações, a opção por aquele que vai resolver o conflito deve levar em conta a força relativa que cada um assume naquele caso em particular. Não se trata de uma asserção, em caráter geral, de que um determinado princípio é mais forte ou de maior relevância que outro, mas sim de uma inferência de que, um dos princípios, naquele caso específico, assume maior peso ou relevância, e não deve ser sacrificado em face dos demais. Por outro lado, as regras jurídicas não apresentam esta dimensão, e não se pode afirmar que uma regra é mais ou menos relevante do que outra na solução de um determinado caso. Se duas regras estão em conflito, uma, simplesmente, suplanta e afasta a outra (7), o que deve ser feito através da aplicação de determinados critérios, tais como o critério da hierarquia, o critério cronológico ou o critério da especialidade. ${ }^{13}$

\footnotetext{
$12 \mathrm{O}$ processo civil rege-se pelo princípio da instrumentalidade das formas, do qual se extrai que as formas, ritos e procedimentos não existem como fins em si mesmos, mas como meios de se garantir um processo justo, equânime, que confira efetividade aos postulados constitucionais da ampla defesa, do contraditório, e do devido processo legal.

${ }^{13}$ Lenio Streck sustenta (10), porém, que cindir regras e princípios é consequência da equivocada classificação entre easy cases e hard cases - acima comentada - já que, como se costuma defender doutrinariamente (15) (16), quando o intérprete estiver diante de casos fáceis, estes seriam resolvidos por mera subsunção às regras, de antemão já dadas pelo legislador. Por outro lado, ao se deparar com hard cases, diante da impossibilidade de aplicação das regras, a resposta só seria plenamente alcançável com a construção de outro tipo de trilha discursiva, notadamente pelo manejo dos princípios, que, paradoxalmente, só vêm à baila nos casos mais complexos e justamente são afastados quando a questão a ser enfrentada é "banal" (9). Ocorre que os chamados casos difíceis, apenas passíveis de determinação já a partir da interpretação do direito, como vimos, não são efetivamente decididos diretamente por princípios, como se estes fossem metaregras que apenas são acionadas diante da insuficiência das regras ordinárias e do processo de subsunção. Em verdade, estes casos
} 
Em verdade, o pensamento de Dworkin reflete sua oposição ao normativismo, ao mundo das regras positivistas, o que concretiza através da adoção de princípios como recursos racionais, evitando, assim, a prevalência de regras que possam ser incoerentes (17). Dworkin estabelece, assim, um confronto entre o legal positivism (positivismo legal) e o chamado interpretivism (interpretativismo), este último argumentando que o direito inclui não só regras específicas criadas conforme as práticas formalmente aceitas pela sociedade, mas também abrange os princípios que fornecem a melhor justificativa moral dessas regras positivadas (18). Há regras, assim, que jamais foram formalmente promulgadas, mas que, por decorrerem destes princípios, são igualmente vinculantes. O interpretativismo, portanto, nesta formulação, aborda o direito como Dworkin o concebe, ou seja: como um conceito interpretativo (19).

Considerando o que desenvolvemos até agora, em que pese o embate os positivistas e o interpretativismo defendido por Dworkin, resta evidente que os juízes, de uma forma geral, dispõem de certa margem de liberdade na escolha dos padrões - políticas, princípios (jurídicos ou até mesmo morais, como veremos adiante) ou regras - que devem utilizar, em alguns casos, para chegar a uma decisão que considerem adequada, o que nos remete ao conceito de "poder discricionário do juiz". Uma vez que os juízes podem decidir os casos que chegam a seu conhecimento através da aplicação das regras jurídicas, dos princípios jurídicos, ou até mesmo a partir de outros padrões, é chegada a hora de investigar com mais atenção este chamado "poder discricionário do juiz".

\section{O poder discricionário do juiz.}

Dworkin e Hart também discordam sobre o tema da discricionariedade judicial, ou do poder discricionário conferido ao juiz. Segundo Dworkin, a discricionariedade, assim entendida como o poder concedido aos juízes de decidirem com ampla liberdade, sem que se vinculem à adoção de soluções iguais para casos semelhantes, é antidemocrática e injusta (20). Hart, por outro lado, defende que no exercício do poder discricionário, o juiz age como um delegado do Poder Legislativo, e que esta delegação não pode ser encarada como

\footnotetext{
devem ser decididos da mesma forma que ocorre com os tidos "casos simples" (17). Leciona Streck, a partir de Dworkin, que nos casos difíceis, a solução final deve ser provida pelo direito como um todo, aí incluídos os princípios, construindose, através da atividade hermenêutica, a norma jurídica adequada ao caso. Portanto, não se pode admitir a idéia de que os casos chamados difíceis seriam aqueles cuja solução decorreria única e exclusivamente incidência de princípios considerados pertinentes que seriam aplicados diretamente e de forma descontextualizada. Trata-se, na visão de Streck, de um grande equívoco (10).
} 
antidemocrática, uma vez que o sistema se encarrega de manter o controle sobre as delegações, além de assegurar mecanismos de revisão das decisões judiciais, em especial as constitucionais. Por fim, Hart, ao contrário de Dworkin, não qualifica como injusta uma norma elaborada pelo juiz pós-fato (esta é uma das objeções que Dworkin faz à possibilidade de os juízes agirem como delegados do Poder Legislativo, como será visto no item que segue). Argumenta que a justiça de uma norma pressupõe uma expectativa, daquele que age, de que as consequências jurídicas de seu ato serão aquelas previstas na própria norma jurídica. Mas isto não ocorre nos casos difíceis, adverte, eis que se trata de situações em que não há um direito claramente estabelecido que possa justificar qualquer expectativa (11).

Deve-se salientar, entretanto, que Dworkin, não nega o poder discricionário dos juízes de uma forma geral e absoluta, mas enfatiza que este poder só pode ser considerado legítimo perante o Estado Democrático de Direito, se a decisão adotada com base nesta prerrogativa se apresentar de forma consistente, construída e formulada de acordo com diretrizes do sistema jurídico, particularmente naqueles casos difíceis, nos quais o direito dos demandantes não se evidencia de forma clara, ou apropriadamente, a partir dos enunciados da lei. Trata-se de uma decisão não arbitrária, que busca conscientemente alcançar um resultado justo e que, para tanto, leva em conta o que é equitativo e razoável, de acordo com as circunstâncias do caso (7). Entretanto, deve ser considerado como um conceito relativo, uma vez que será sempre afirmado em relação a determinados padrões que são estabelecidos por determinada autoridade, em um certo caso.

Ronald Dworkin adverte, ainda, que a expressão "poder discricionário" pode ser empregada e compreendida em três sentidos, os dois primeiros considerados fracos, e o terceiro considerado forte (7):

1. Algumas vezes empregamos "poder discricionário" apenas para afirmar que, por alguma razão, os padrões que uma autoridade pública deve adotar não podem ser aplicados mecanicamente, mas exigem o uso da capacidade de julgar. É utilizado quando o contexto não é, por si só esclarecedor, uma vez que a própria norma apresenta uma textura aberta ou conceitos vagos, que admitem, assim, duas ou mais possíveis linhas de interpretação.

2. Há casos em que a expressão é utilizada para apenas para dizer que determinada autoridade pública detém a prerrogativa para tomar uma decisão 
em última instância e que, portanto, não poderá mais ser revista ou alterada por nenhuma outra autoridade.

3. A expressão, no seu sentido mais forte, é utilizada para afirmar que, em determinadas matérias a autoridade não está limitada a decidir com base no padrão $A$ ou $B$, uma vez que lhe é conferida liberdade para decidir sobre o padrão a ser utilizado. Assim, neste caso, o "poder discricionário" não é aludido, simplesmente, para ressaltar o caráter vago dos padrões, ou ainda, para identificar aquele que tem a última palavra para aplicação deles, mas sim para decidir sobre seu âmbito de aplicação nas decisões que a serem tomadas. É precisamente este o sentido que adotamos neste estudo, quando nos referimos ao poder discricionário dos juízes, em particular quando são chamados a decidir casos difíceis em matéria de saúde, diante das situações que já definimos como de conflito moral.

Mas até onde vai a discricionariedade dos juízes? Será que podem decidir livremente, de acordo com as regras jurídicas, princípios jurídicos, política, ou mesmo de acordo com suas convicções morais, a seu único e exclusivo talante? Veremos, nos próximos itens, que a doutrina diverge sobre esta questão.

\section{Controvérsia entre Dworkin e Hart: a tese dos direitos.}

De acordo com a doutrina de Dworkin, se um caso não pode ser adequadamente decidido com base em uma regra jurídica pré-estabelecida, o juiz deverá decidi-lo exercendo seu poder discricionário, com as limitações acima vistas, fazendo uso, inclusive, de outros padrões, diferentes das regras jurídicas. Entretanto, o autor, afirma que mesmo quando nenhuma regra jurídica ou princípio de direito se apresenta como solução clara da questão, nos chamados casos difíceis, os juízes continuam tendo o dever de aplicar o direito criado por outras instituições (em nosso caso, o Poder Legislativo), e não devem, a partir da utilização do padrão da política, "criar" um novo direito. Segundo o autor, os juízes não são legisladores, e não podem agir como se fossem delegados do Poder legislativo, promulgando as leis que, em sua opinião, os legisladores promulgariam caso se vissem diante do problema (7).

Dworkin acrescenta que um sistema legal complexo deverá exigir argumentos dos dois tipos para encontrar justificação social. A inexistência de argumentos de princípio, observa 
o autor, causará insegurança, uma vez que todo e qualquer direito poderá ser relativizado quando as consequências de sua aplicação afrontarem uma política pública (13). Aqui, portanto, mais uma divergência à tese de Hart. Seguindo esta orientação, Dworkin desenvolve uma tese que denomina como tese dos direitos, pela qual defende que os juízes, mesmo em casos difíceis, devem decidir com base nas regras jurídicas, ou nos princípios jurídicos, mas não com base em argumentação política. Salienta que, nestes casos, o juiz deve interpretar o direito do passado - os precedentes ${ }^{14}$ - para descobrir quais princípios melhor o justificam, e, em seguida, concluir o processo decisório identificando a solução que estes princípios indicam para o novo caso. Tendo em conta a necessária preservação do princípio da democracia, sustenta seu posicionamento a partir de algumas objeções que faz à originalidade judicial (7):

1. Uma comunidade deve ser governada por pessoas eleitas pela maioria da população, que assumem, portanto, responsabilidade perante seus eleitores. Como os juízes não são eleitos e, portanto, não são responsáveis perante o eleitorado, como ocorre com os legisladores, o pressuposto acima fica comprometido quando os juízes criam leis.

2. Se o juiz cria uma nova lei para aplicá-la ao caso submetido à sua jurisdição (norma pós-fato), estará aplicando a lei de forma retroativa, e punindo a parte vencida pela imposição de um dever criado pelo juiz após a ocorrência do fato, o que cria insegurança jurídica.

3. As decisões sobre políticas devem ser operadas através de um processo que ofereça oportunidade para expressão exata dos diferentes interesses que devem ser levados em consideração, com debates e ampla discussão. São possibilidades facilmente viabilizadas nas casas legislativas, mas de impossível concretização nos gabinetes dos juízes ou em suas salas de audiência.

\footnotetext{
${ }^{14}$ Dworkin, evidentemente, está se referindo ao sistema jurídico norte-americano, conhecido como common law, em que o direito se revela a partir dos costumes, e por meio das decisões dos tribunais -os chamados precedentes -, e não mediante atos legislativos, as leis propriamente ditas, ou executivos, os chamados atos administrativos, tais como decretos, regulamentos, portarias, instruções normativas, etc. Constitui, portanto, um sistema marcadamente diferente daquele adotado entre nós, o romano-germânico, que enfatiza os atos legislativos e executivos. Apesar disso, nada impede que a teoria desenvolvida pelo autor seja adotada em nosso marco teórico, desde que tenhamos consciência desta diferença. Também é importante ressaltar que o novo Código de Processo Civil brasileiro introduziu uma série de alterações na legislação processual civil, algumas delas com o claro objetivo de reforçar a influência e a relevância dos precedentes nas decisões judiciais, o que contribui para aproximar as duas linhas de orientação, ao menos em nosso país.
} 
4. Um argumento de princípio, ou com base em regra jurídica, estipula alguma vantagem apresentada por quem reivindica o direito que 0 argumento descreve, uma vantagem cuja natureza torna irrelevantes quaisquer argumentos de política que a ela pudesse se opor. Assim, o juiz, que não é pressionado pelas demandas da maioria política, que gostaria de ver seus interesses protegidos pelo direito, encontra-se em melhor posição para avaliar 0 argumento.

Para melhor compreensão da objeção número 4, tomemos o caso de uma pessoa que pede em juízo que o Estado Ihe forneça um determinado medicamento, preenchidas todas as exigências legais. O requerente invoca, como causa de pedir, o seu direito ao medicamento com base na Constituição Federal e na legislação do SUS, demonstrando, inclusive, que preenche os requisitos exigidos pela referida legislação. Pois bem, a Fazenda poderá arguir que esta lei não é boa, que já deveria estar revogada, que o medicamento em questão já deveria ter sido substituído nas listas oficiais, que o custo é muito elevado e impactará sobremaneira as contas públicas, etc. Nada disso, em princípio, deveria impressionar o magistrado como tese de defesa, eis que são todos argumentos de política, e o direito do demandante ao medicamento em questão não depende mais de qualquer fundamentação política, já que a lei o transformou em uma questão de princípio (aqui em sentido amplo, abarcando, portanto, as regras jurídicas). Os fundamentos políticos que orientaram a edição da lei em questão podem até não mais subsistir, tendo razão, neste ponto, a Fazenda, mas enquanto a lei estiver em vigor, há que se preservar o direito individual. Portanto, para Dworkin, é certo que as decisões judiciais que aplicam a um determinado caso uma norma previamente estabelecida, adotam, como base, argumentos de princípio, ainda que a lei aplicada tenha sido editada com fundamento em alguma política (21).

Ainda respondendo às questões acima lançadas, acerca dos limites que dever ser impostos à chamada discricionariedade dos juízes, devemos, agora, avaliar a liberdade que os juízes devem ou não ter de decidir segundo suas convicções morais. Para tanto, iremos a explorar a teoria de Dworkin, no contexto de suas divergências com Hart e Posner, mais especificamente no que diz respeito às conexões entre a moral e o direito. 


\section{As conexões entre o direito e a moral. A influência das convicções morais do julgador em suas decisões: as divergências de Dworkin com Hart e Posner.}

O debate entre as possíveis conexões entre a moral e o direito é velho conhecido dos filósofos, e importantes delimitações já foram estabelecidas entre um e outro campo teórico. Ao enfrentar esta recorrente questão, Dworkin descreve o direito não como um sistema de regras que pode, por vezes, conflitar com a moralidade, mas sim como um verdadeiro ramo da moralidade (a branch of morality ${ }^{15}$ ). A título de ilustração, Dworkin sugere que a moralidade em geral tem a estrutura de uma árvore: o direito seria um galho da moralidade política; a moralidade política seria um galho de uma moral pessoal mais abrangente; e essa moral pessoal seria por sua vez um galho de uma teoria ainda mais abrangente do que seja bem viver (19). ${ }^{16}$

Por outro lado, o positivismo jurídico de Hart declara a completa independência entre direito e moral. Sob este ponto de vista, o direito depende, da aceitação (costume e práticas) de uma determinada comunidade. Se uma regra é produzida de acordo com os padrões admitidos pela comunidade (por exemplo, pelo fato ter sido editada respeitando-se as diretrizes fixadas nas regras secundárias acima referidas), então pouco importa se é justa ou injusta: em todo o caso, será considerada direito (19).

Não há dúvida de que os juízes, frequentemente, no julgamento dos chamados casos difíceis, são obrigados a enfrentar importantes questões de natureza moral, ou questões morais ${ }^{17}$, para que possam dar uma solução ao feito. O ponto que nos interessa, agora, está em saber como as convicções morais de um juiz podem influenciar suas decisões? Juristas, sociólogos, filósofos do direito, políticos e juízes oferecem respostas diferentes a esta questão que vão de "nada" a "tudo" (12).

\footnotetext{
${ }^{15}$ Como bem observa Francisco José Borges Motta, é preciso redobrada cautela para que não se confunda, no contexto da obra de Dworkin, o direito com a moral. Não é de subordinação que trata a tese do direito como branch of morality. O autor adverte que toda a literatura dworkiniana é guiada por um alto de grau de autonomia do direito (19).

${ }_{16}$ Dworkin observa que não se pode tomar o direito e a moral como sistemas separados, uma vez que não há um ponto de vista neutro de onde se possam fazer as conexões entre um e outro. O que há é circularidade. Qualquer pergunta que se faça sobre as relações entre direito e moral, ao presumir a separação entre estes dois sistemas, não pode ser respondida, a não ser que já se saiba uma resposta de antemão (19). A resposta depende de uma teoria, e não se tem uma teoria sem que se tenha, previamente, alguma perspectiva a respeito do papel que a moralidade desempenha no Direito (18).

${ }^{17}$ Trata-se de questões que provocam um questionamento íntimo acerca dos princípios e das convicções pessoais de cada um, e que podem provocar reações totalmente diferentes, dependendo de quem as avalia, da sua sensibilidade, do seu caráter, ideologia, crenças, etc. Não há maiores dúvidas de que o tema está intimamente relacionado com os conflitos morais de que estamos tratando com mais interesse neste projeto, uma vez que também aqui o juiz estará diante de uma inevitável ponderação de interesses, quais sejam: o interesse de prestigiar as regras jurídicas e o interesse de seguir a sua íntima convicção a respeito do que considera justo, correto ou sensato para o caso em questão.
} 
Em importante debate doutrinário Richard A. Posner e Ronald Dworkin abordaram a questão do enfrentamento de questões morais pelos juízes, o primeiro defendendo que tais questões devem ser ignoradas pelos juízes, que dispõem de melhores recursos para atingir seus objetivos. Segundo Posner, na Inglaterra, o direito é uma disciplina autônoma, e tais questões são resolvidas, em grande parte, pela interpretação de textos autorizados, que consistem em leis, regulamentações e decisões judiciais - os precedentes -, sendo certo que nenhuma destas fontes incorpora uma teoria moral (22). Defendendo posicionamento oposto, Ronald Dworkin adverte que se os juízes são obrigados a lidar com questões morais, e isto é um fato, como dizer que devem resolvê-las através da história, da economia, da álgebra, ou de qualquer outra técnica que não a própria moral?!?

Sobre o tema, também divergem Ronald Dworkin e H.L.A Hart, eis que para Dworkin o argumento jurídico é um argumento típica e completamente moral, assim, os juízes, ao decidirem, devem identificar que princípios (ou regras jurídicas) oferecem a melhor justificação da prática jurídica, segundo as suas convicções morais (12). Por outro lado, em seu pós-escrito ${ }^{18}$, Hart salienta que, de acordo com sua teoria, a existência e o conteúdo do direito podem ser identificados por meio de referências às chamadas fontes sociais do direito como, por exemplo, a legislação, a jurisprudência, os costumes sociais, mas sem qualquer referência à moral, a não ser nos casos em que o próprio direito tenha incorporado critérios morais (11). Hart admite, portanto, que há um vínculo necessário entre moral e o direito, nas hipóteses em que se verifica a incorporação de valores morais substantivos como critérios últimos de validade jurídica. Segundo o autor, nenhum "positivista" poderia, simplesmente, ignorar que a estabilidade dos sistemas jurídicos depende, ao menos em parte, dessa vinculação entre o direito e a moral (23). No entanto, Dworkin e Hart divergem, claramente, no que diz respeito a determinar até que ponto e em que sentido os juízes devem emitir seus próprios "juízos de valor" no julgamento dos casos difíceis.

Como se depreende da tese de Hart, ao contrário do pensamento de Dworkin, as convicções morais do julgador só poderão influir no julgamento quando as fontes sociais do direito acima referidas tornam os critérios morais parte do direito, incorporando-as. Já

\footnotetext{
${ }^{18}$ Hart dedicou os últimos dez anos de sua vida para elaborar uma resposta detalhada às objeções de Ronald Dworkin, destacando várias pontos de discordância observados em suas teorias sobre o direito, desde a publicação da primeira edição de seu livro, The Concept of Law, em 1961. Infelizmente, Hart não teve tempo para a publicá-la, eis que faleceu em 1994. No entanto, Joseph Raz e Penelope Bullock receberam, da família de Hart, um rascunho que foi revisado, organizado e publicado como pós-escrito à segunda edição do livro The Concept of Law.
} 
Dworkin adverte que a moral interfere de forma significativa sobre o direito, assim entendido, sob a perspectiva estrutural acima definida, como um sistema de regras e princípios jurídicos (12), de três formas:

1. Algumas constituições impõem limites morais a quaisquer leis que possam ser validamente criadas no respectivo ordenamento jurídico, e assim, uma vez incorporado, pelo texto constitucional, um dado padrão de moralidade, ficam a ele vinculadas - ao menos em caso - todas as instâncias dos três poderes. Deve ser observado que este padrão de interferência é o único admitido por Hart, como acima restou evidenciado.

2. A interpretação ${ }^{19} 20$ a ser conferida pelos juízes a uma dada proposição de direito (regra jurídica ou princípio jurídico) será admitida desde que decorra de princípios de moralidade pessoal que ofereçam a melhor interpretação das demais proposições de direito admitidas pela prática jurídica. Portanto, sob essa perspectiva, a compreensão, o entendimento que o magistrado terá em relação ao texto legal, será definido a partir suas convicções morais.

3. Os juízes têm o dever moral de ignorar a lei quando a considerem muito injusta ou insensata. Em princípio, as pessoas, de uma forma geral, esperam que os juízes decidam aplicando a lei, mas, em casos excepcionais, os juízes devem, de fato, repudiá-la. Portanto, se é verdade que a prática jurídica observa, como regra, a aplicação da lei, também é possível afirmar, com o mesmo grau de coesão, que os juízes nunca devem aplicar a lei, a menos que considerem, sem nenhuma influência externa, a lei como uma formulação justa, sábia ou eficiente.

\footnotetext{
${ }^{19}$ Como já salientamos em nota anterior, a aplicação da lei reflete, na verdade, o ato final de um processo decisório, que se inicia com o conhecimento dos fatos e a interpretação da lei. A palavra "interpretação" tem sentido próprio no âmbito jurídico, e diz respeito à atividade de busca, empreendida pelo magistrado - ou outro intérprete -, do verdadeiro alcance e significado da norma. Trata-se de uma reflexão acerca da melhor compreensão que deve ser atribuída ao texto legal. Assim, enquanto "interpretar" quer dizer uma atividade, "hermenêutica" tem sentido distinto, uma vez que nos remete a uma ciência, a ciência que se dedica ao estudo das diversas técnicas de interpretação. Após interpretada, a lei deve ser aplicada, etapa final do processo, quando então, após a subsunção da norma ao caso concreto, o juiz estará decidindo a questão.

${ }^{20}$ Como observa Francisco José Borges Motta, Dworkin não considera a interpretação jurídica como uma atividade sui generis, destinada a descobrir o significado de um texto, mas, isso sim, como uma atividade geral, operada de igual forma em outros contextos. Dworkin usa a interpretação literária como modelo para o modo central da análise jurídica, argumento que ilustra a partir do seguinte exercício literário: cada romancista deverá criar um capítulo subsequente de uma obra coletiva, assumindo com seriedade a responsabilidade de criar, o quanto possível, um romance único, integrado, ao invés, por exemplo, de uma série de contos independentes com personagens desse nome (19). Resumindo, para Dworkin, "decidir casos controversos no Direito é mais ou menos como esse estranho exercício literário". (24).
} 
Assim, de acordo com a tese de Dworkin, além dos casos em que o próprio ordenamento jurídico, através de suas regras e princípios, incorpora e impõe padrões de moralidade, as convicções morais pessoais dos juízes poderão influenciar suas decisões tanto no momento em que interpretam as regras e princípios jurídicos, como também no momento em que afastam a lei, cuja aplicação, naquele caso concreto, se revela injusta, segundo um juízo de valor próprio.

Pois bem, ao aceitarmos as possibilidades de acima enfatizadas, surgem importantes questões a serem respondidas:

1. Uma vez que o juiz, no âmbito de sua discricionariedade, pode interpretar a lei ou mesmo afastar a sua aplicação, com base em suas convicções morais, como deverá fundamentar sua decisão?

2. Neste caso, experimenta um conflito moral?

3. Será aceitável que sua decisão seja justificada por sua religiosidade, suas crenças, seu entendimento sobre o que é certo ou errado, justo ou injusto?

Para respondermos a essas indagações torna-se imprescindível uma abordagem, ainda que sucinta, acerca da teoria da argumentação jurídica ${ }^{21}$, eis que o processo de decisão precisa ser fundado em uma ótica racional do conjunto de ideias que o compõe, para que possa oferecer respostas confiáveis aos operadores do direito. Segundo Robert Alexy, o conceito de argumentação jurídica racional encontra suas bases em uma série de regras a serem seguidas, e de formas que devem ser adotadas no processo decisório, para que o resultado alcançado possa ser considerado correto. As regras e formas do discurso jurídico constituem, por este motivo, critério de correção para as decisões jurídicas (25). Interessa-nos mais a fundo, nesse particular, a teoria da argumentação de Manuel Atienza, que destacaremos a seguir, ao menos nos pontos que se vinculam de forma mais direta ao desenvolvimento deste projeto.

\footnotetext{
${ }^{21} \mathrm{~A}$ exigência de racionalidade na interpretação e aplicação do Direito é objeto de reflexão da teoria da argumentação jurídica, cujo pressuposto básico é a concepção do discurso jurídico como forma especial do discurso prático geral. Seguindo esta linha de pensamento, procura-se garantir que as decisões jurídicas sejam adotadas a partir de critérios racionais, através da utilização de um procedimento igualmente racional. Robert Alexy e Neil MacCormick compartilham da mesma preocupação com a justificação das decisões jurídicas e, no entender de ambos, ela é pautada pela adoção de critérios racionais por parte do juízo decisório. Ambos se dedicam a estabelecer técnicas de interpretação e aplicação da norma jurídica que assegurem racionalidade às decisões (MACCORMICK, 2006; ALEXY, 2011).
} 


\section{Teoria da argumentação jurídica de Manuel Atienza.}

Manuel Atienza adverte que o direito, enquanto ciência argumentativa, exige que seu operador compreenda que a argumentação jurídica é diferente de todas as demais modalidades de argumentação, pois, como o próprio termo o afirma, é jurídica. Em se tratando de juízes, esta compreensão é fundamental, pois nenhum juiz deve proferir qualquer decisão sem fundamento ou motivação, ou seja, sem declinar as razões que concorreram para formar seu convencimento. Segundo o autor, a argumentação jurídica pode ser vista de acordo com três concepções distintas: formal, material e pragmática (8). ${ }^{22}$

Segundo o autor, a justificação de uma decisão não deve encontrar seus fundamentos na estrutura da decisão (concepção argumentativa formal), ou nos efeitos produzidos (concepção argumentativa pragmática), mas sim nas boas razões (concepção argumentativa material) que levaram o magistrado a decidir naquele sentido (26).

A teoria da argumentação jurídica de Manuel Atienza também trata do tema da influência das convicções morais de um juiz em suas decisões, acima visto, nos auxiliando, portanto, a responder às indagações que acima formulamos. Mas, antes, é preciso reconhecer os três campos ou âmbitos de atuação de uma teoria de argumentação jurídica, a saber: a produção ou o estabelecimento de normas jurídicas, a aplicação de normas jurídicas e a dogmática jurídica. Em cada um desses âmbitos, de maneira categorizada, se desdobra o contexto de descoberta e o contexto de justificação, os quais, por sua vez, desenvolvem-se nos discursos descritivos e prescritivos $(26)^{23}$.

\footnotetext{
${ }^{22}$ Segundo a concepção argumentativa formal, prevalece a lógica dedutiva, em que a preocupação do operador limita-se a garantir a existência de uma correlação lógica entre as premissas e as conclusões, deixando claro o "caminho" percorrido pelo julgador para, partindo das primeiras, chegar às últimas. Trata-se, assim, de um esquema argumentativo despreocupado com a realidade, ou com uma expressão crítica do resultado, bastando que o operador jurídico demonstre que interpretou e aplicou a lei, construindo-se, assim, ao menos do ponto de vista estrutural, seu argumento (26). Segundo a concepção argumentativa material, o foco da atividade desenvolvida pelo operador do direito está no conteúdo do problema, analisado de forma crítica e comprometida com o interesse de se chegar a uma conclusão correta. Não se trata, portanto, de uma simples prática de argumentação jurídica do ponto de vista formal acima visto, mas sim de uma atividade que busca obter um objeto lastreado em uma teoria de argumentação consistente, que obedeça a critérios científicos (26), e alcance, de fato, uma decisão que preenche requisitos tais como a correição, a justiça, a sensatez, e não seja apenas um caminho aceitável do ponto de vista da lógica. Já sob a ótica da concepção argumentativa pragmática, a atenção do operador se concentra nos efeitos produzidos pela argumentação, de modo que sua preocupação ultrapassa a mera esfera subjetiva individual do operador, e passa a atuar sobre a esfera do outro, tentando convencê-lo, persuadi-lo, de que sua solução para o caso é a melhor. Assim, segundo este ponto de vista a argumentação jurídica será tão boa quanto maior for seu potencial de convencer terceiros sobre a adequação da tese adotada (26).

${ }^{23} \mathrm{O}$ âmbito da produção jurídica ou do estabelecimento da norma jurídica se desenvolve quase que inteiramente na seara legislativa, salientando-se, no entanto, a existência de uma etapa pré-legislativa, em que ocorrem debates a respeito de um determinado problema social. Desta discussão pode resultar a criação ou modificação de leis. No âmbito da aplicação da norma jurídica, desenvolve-se a atividade desempenhada pelos juízes, e também dos órgãos administrativos, subsumindo-se a lei ao caso concreto. Por fim, no âmbito da dogmática há uma análise genérica do ordenamento jurídico, diferindo da aplicação da norma porque não se destina a resolver casos concretos, atendo-se a casos abstratos. A
} 
É preciso, ainda, compreender os contextos da descoberta da justificação. Para Atienza, o contexto da descoberta implica em explicar, sem, contudo, justificar. Enquanto a explicação é feita através de princípios morais, a justificação exige uma fundamentação propriamente dita, baseada em regras científicas. Os juízes, ao proferirem suas decisões, conforme disposto no art. 93, inciso IX, da Constituição Federal, devem fundamentar suas decisões, sob pena de nulidade. Percebe-se, assim, que as decisões judiciais devem se desenvolver no contexto de justificação, isto é, tendo como base a fundamentação jurídica por indução ou dedução, e não no contexto da descoberta. Se um juiz apresentar, como justificativa de sua decisão, as suas convicções religiosas, ou seu entendimento particular sobre o que é correto ou justo, não está fundamentando sua decisão, não está justificando, mas somente explicando, e neste ponto, resta evidente que experimenta um conflito moral. Portanto, respondendo às nossas indagações, ainda que os juízes decidam premidos por suas convicções morais, experimentando situações de conflito íntimo, devem, segundo a concepção argumentativa material preconizada por Manuel Atienza, fundamentar sua decisão com base em outras justificativas, e é o que ocorre na prática, como veremos a seguir, para, assim, concluirmos nossa abordagem teórica neste estudo.

\section{Considerações Finais}

Como já vimos, os juízes, em determinadas situações na tutela judicial da saúde, poderão experimentar conflitos morais, sendo instados a ponderar o interesse da aplicação da lei, da jurisprudência, ou dos princípios jurídicos, com outros padrões, tais como a política ou as suas próprias conviç̧ões morais, neste particular quando diante de questões que provocam um questionamento íntimo acerca dos princípios e das convicções pessoais de cada um, e que podem provocar reações totalmente diferentes, dependendo de quem as avalia, da sua sensibilidade, do seu caráter, ideologia, crenças, etc.

Tais questões, quando submetidas à apreciação de qualquer pessoa (incluídos os juízes), provocam um juízo de censura, ou de aprovação, de certo, ou de errado, de justo ou de injusto, que bem caracteriza o discurso ou argumentação moral. Não comportam, por outro lado, valoração do tipo verdadeiro ou falso - como seria o caso de uma asserção da física ou da matemática -, mas sim um juízo de valor, de acordo com princípios morais de

dogmática jurídica se destina a fornecer critérios para a produção e aplicação do direito, além de ordenar e sistematizar o ordenamento jurídico (26). 
cada um. Todas as pessoas, de uma forma geral, ainda que de uma forma mais ou menos reflexiva, têm suas opiniões sobre o aborto, a eutanásia, a educação dos filhos, etc, e as expressam sob a forma um discurso de natureza prescritiva, sobre como agir, como ser justo, correto ou sensato. No entanto, não raro, estas opiniões são manifestadas sem maiores preocupações, sem que decorram, verdadeiramente, de uma reflexão profunda e isenta sobre o tema, e não representem uma mera projeção das emoções e convicções pessoais sobre os acontecimentos da vida. Em muitos casos, as pessoas ficam até impacientes quando questionadas sobre a coerência de sua orientação: elas simplesmente separam o "certo" do "errado", o "justo" do "injusto", e "não querem ser perturbadas por dúvidas ou insinuações de incoerência" (12).

Evidentemente, não é esta a postura que se espera de um juiz ao enfrentar questões dessa natureza, em primeiro lugar, porque tem o dever imposto pela Constituição Federal ${ }^{24}$ de fundamentar suas decisões, e não apenas de explicá-las - como visto como tratamos da teoria da argumentação jurídica de Manuel Atienza; em segundo lugar, porque aprecia estas questões como um pressuposto lógico da questão de mérito, que pode dizer respeito à vida, à liberdade ou à saúde de outrem. Portanto, sua responsabilidade ao se manifestar sobre as mesmas é indiscutivelmente maior, e exige uma reflexão mais cuidadosa e ponderada. Isto não quer dizer que deva sair em busca de respostas definitivas, com fundamentos capazes de convencer a todos, até porque isto será de todo impossível em se tratando de temas que não admitem, como já visto, asserções do tipo "verdadeiro" ou "falso", mas sim juízos de valor, profundamente arraigados às convicções pessoais de cada um.

Assim, os juízes, seres humanos que são, ao se defrontarem com estas situações, estarão igualmente premidos por suas convicções pessoais, pelos próprios princípios morais, e nem sempre se sentirão "confortáveis" em adotar a solução eventualmente apontada pela simples aplicação da lei - quando a lei não for omissa em relação a esses casos - que pode ir de encontro a seus princípios e convicções pessoais. Experimentam, portanto, situações de conflito, uma vez que são instados a deliberar sobre situações cuja solução não depende de maiores divagações sobre as normas e princípios jurídicos, como ocorre nos casos comuns, mas que poderão desafiar seus valores enquanto pessoa, sua convicção sobre a justiça, sobre o certo e o errado. São casos em que os juízes devem

24 BRASIL. Constituição da República Federativa do Brasil de 1988, artigo 93, inciso IX. Disponível em: <https://www.planalto.gov.br/ccivil_03/constituicao/constituicao.htm>. Acesso em: 22 dez. 2016. 
decidir, mais em função de sua sensibilidade enquanto ser humano, do que com base em seus vastos conhecimentos sobre as leis e a ordem jurídica. Assim, a argumentação utilizada para fundamentar tais decisões, não pode, simplesmente, retratar as convicções morais do julgador, como acima visto, mas tampouco refletirá o tradicional discurso técnico-jurídico, evidenciando-se, claramente, um discurso moral. Desta forma, a existência destes conflitos pessoais, íntimos do magistrado, poderá ser revelada, por alguns indícios a serem observados na argumentação utilizada:

a) Utilização de expressões de menor densidade jurídica, a expressar uma avaliação puramente subjetiva, tais como "é razoável", "não é proporcional", "é justo", etc.

b) Adoção de critérios que mais expressam sentimentos humanitários de solidariedade, justiça e preocupação com o bem-estar do próximo, que, embora louváveis, se revelam distantes de qualquer acepção técnicojurídica. Nesta linha, algumas decisões são justificadas pelo intuito de proteger os mais pobres, as crianças, aos portadores de deficiência, etc.

c) A simples utilização de princípios gerais do direito de forma vaga e imprecisa, que aparecem como formulações genéricas hábeis a justificar toda e qualquer decisão, sem que haja o enfrentamento efetivo das peculiaridades do caso concreto.

d) O recurso a fontes doutrinárias que militam no campo da filosofia, estranhas ao direito enquanto disciplina.

Além destes indícios a serem observados na argumentação utilizada pelos juízes, a existência de conflitos morais experimentados pelos juízes também pode ser evidenciada a partir da verificação de soluções radicalmente diferentes para casos idênticos. É bem verdade que uma certa oscilação da jurisprudência, que decorre de diferentes interpretações conferidas à lei, é sempre esperada e considerada normal, mas diante de questões morais, em que cada magistrado decidirá de acordo com seus princípios e convicções pessoais, que nem sempre coincidirão com aqueles adotados por seus pares, a divergência deverá assumir uma amplitude ainda mais significativa.

Nas situações que apresentamos como casos difíceis em matéria de saúde, observamos, com muita frequência, a existência dos indícios acima discriminados na argumentação utilizada pelos magistrados. Da mesma forma, é muito comum, nestes casos, 
encontramos na jurisprudência decisões totalmente divergentes para casos idênticos. Tomemos como exemplo a situação em que um paciente que apresenta quadro de doença que não vem respondendo aos tratamentos oferecidos pelo SUS, requer, judicialmente, sob alegação de risco de vida comprovado em laudo médico, o fornecimento de medicamento sem registro na ANVISA. A questão, se enfrentada pela lógica jurídica tradicional, não comportaria maiores digressões ou dificuldades, eis que a improcedência do pedido resultaria da simples aplicação da lei. Encontramos, no entanto, diversos julgados, em que os juízes vêm deferindo os medicamentos requeridos com base em discurso moral típico, como acima detalhamos, sem apresentar, no entanto, qualquer argumentação de natureza jurídica a sustentar a não-aplicação da lei. ${ }^{25}$ De outro lado, em outros julgados, constatamos decisões inteiramente divergentes, denegando o pedido de medicamentos, para casos semelhantes $^{26}$, o que corrobora a tese de existência de um conflito moral experimentado pelos magistrados nestas questões que retratam casos difíceis em matéria de saúde.

\section{Referências}

1. Dworkin, R. A Virtude Soberana. A teoria e a prática da igualdade. São Paulo: Martins Fontes Editora, 2005.

2. Brasil. Supremo Tribunal Federal. Agravo Regimental na Suspensão de Tutela

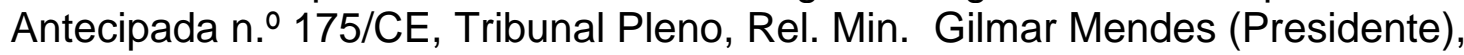
j.17/03/2010, DJe 30/04/2010, p. 070.

3. Brasil. Constituição da República Federativa do Brasil de 1988. Brasília, 05 de outubro de 1988. [Acesso em 29 dez 2016]. Disponível em: http://www.planalto.gov.br/ccivil_03/Constituicao/Constituicao.htm.

\footnotetext{
${ }^{25}$ A título de exemplo, confiram-se os seguintes julgados: TRF4 - QUARTA TURMA - AGRAVO DE INSTRUMENTO 5041197-36.2016.404.0000/SC - Relator DESEMBARGADOR FEDERAL LUÍS ALBERTO D'AZEVEDO AURVALLE julgamento: 14/12/2016; TRF3 - QUARTA TURMA - AGRAVO DE INSTRUMENTO 571341/SP - Relator DESEMBARGADOR FEDERAL MARCELO SARAIVA - julgamento: 03/08/2016 e-DJF3 Judicial:18/08/2016; TRF3 TERCEIRA TURMA - AGRAVO DE INSTRUMENTO 574047/SP - Relator DESEMBARGADOR FEDERAL ANTONIO CEDENHO - julgamento: 01/12/2016 e-DJF3 Judicial:12/12/2016; TRF3 - QUARTA TURMA - AGRAVO DE INSTRUMENTO 577581/SP - Relator DESEMBARGADOR FEDERAL ANDRE NABARRETE - julgamento: 19/10/2016 eDJF3 Judicial: 08/11/2016; TRF5 PRIMEIRA TURMA AGRAVO DE INSTRUMENTO 08054911720164050000/SE - Relator DESEMBARGADOR FEDERAL RODRIGO VASCONCELOS COELHO DE ARAÚJO (Convocado) - julgamento: 06/12/2016.

${ }^{26}$ Confiram-se os seguintes julgados: TRF2 - SÉTIMA TURMA ESPECIALIZADA - AGRAVO DE INSTRUMENTO 2016.00.00.008669-0 - Relator DESEMBARGADOR FEDERAL JOSÉ ANTONIO NEIVA - julgamento: 18/11/2016; TRF2 SEXTA TURMA ESPECIALIZADA - AGRAVO DE INSTRUMENTO 2016.00.00.006741-5 - Relator DESEMBARGADOR FEDERAL NIZETE LOBATO CARMO - julgamento: 24/11/2016; TRF2 - SEXTA TURMA ESPECIALIZADA - AGRAVO DE INSTRUMENTO 2016.00.00.006741-5 - Relator DESEMBARGADOR FEDERAL NIZETE LOBATO CARMO - julgamento: 24/11/2016.
} 
4. Brasil. Lei $n . \circ 8.080$ de 19 de setembro de 1990. Dispõe sobre as condições para a promoção, proteção e recuperação da saúde, a organização e o funcionamento dos serviços correspondentes e dá outras providências. Brasília, 19 de setembro de 1990. [Acesso em 29 dez 2016]. Disponível em: https://www.planalto.gov.br/ccivil_03/leis/L8080.htm.

5. Brasil. Lei n. 8.142 de 28 de dezembro de 1990. Dispõe sobre a participação da comunidade na gestão do Sistema Único de Saúde (SUS\} e sobre as transferências intergovernamentais de recursos financeiros na área da saúde e dá outras providências. Brasília, 28 de dezembro de 1990. [Acesso em 29 dez 2016]. Disponível em: http://www.planalto.gov.br/ccivil_03/leis/L8142.htm.

6. Freitag, B. A questão da moralidade: da razão prática de Kant à ética discursiva de Habermas. Tempo Social - Rev. Sociologia da USP. 1989; 1(2):1-32.

7. Dworkin, R. Levando os direitos a sério. 3. ed. São Paulo: Martins Fontes Editora, 2010.

8. Atienza, M. Curso de argumentación jurídica. Madrid: Editorial Trotta, 2013.

9. Caldeira, APC. O direito à saúde e sua "curiosa" efetividade em Terrae Brasilis: do desafio da realização da boa governança à excessiva judicialização [Tese]. São Leopoldo: Programa de Pós-Graduação em Direito,Universidade do Vale do Rio dos Sinos Unisinos, 2013. [Acesso em 10 jan 2017]. Disponível em:

https://sucupira.capes.gov.br/sucupira/public/consultas/coleta/trabalhoConclusao/viewTrab alhoConclusao.jsf?popup=true\&id_trabalho=135330.

10. Streck, LL. Verdade e consenso: constituição, hermenêutica e teorias discursivas. Rio de Janeiro: Lumen Juris, 2006.

11. Hart, HLA. O conceito de direito. Lisboa: Gulbenkian; 1994.

12. Dworkin, R. A justiça de toga. São Paulo: Martins Fontes Editora, 2010.

13. Machado, TRC. A necessidade de justificação ética e fática dos argumentos trazidos ao debate sobre judicialização da saúde no Brasil [Tese]. Rio de Janeiro: Escola Nacional de Saúde Pública Sergio Arouca, 2015. . [Acesso em 10 jan 2017]. Disponível em: http://www.arca.fiocruz.br/xmlui/handle/icict/12981.

14. Mendes, G F. Curso de direito constitucional. 4. ed. rev. e atual. São Paulo: Saraiva, 2009.

15. Barcellos, AP. A Eficácia jurídica dos princípios constitucionais: o princípio da dignidade da pessoa humana. Rio de Janeiro: Renovar, 2002.

16. Sarmento, D. A ponderação de interesses na Constituição Federal. Rio de Janeiro: Lumen Juris, 2002. 
17. Madalena, LHB. A discricionariedade (administrativa) à luz da crítica hermenêutica do direito. [Dissertação]. São Leopoldo: Programa de Pós-Graduação em

Direito,Universidade do Vale do Rio dos Sinos - Unisinos, 2014. [Acesso em 10 jan 2017]. Disponível em:

https://sucupira.capes.gov.br/sucupira/public/consultas/coleta/trabalhoConclusao/viewTrab alhoConclusao.jsf?popup=true\&id_trabalho=1395584.

18. Dworkin, R. Justice for hedgehogs. Cambridge, Massachusetts, London: The Belknap Harvard University Press, 2011.

19. Motta, FJB. Ronald Dworkin e a construção de uma teoria hermeneuticamente adequada da decisão jurídica democrática. [Tese] (doutorado). São Leopoldo: Programa de Pós-Graduação em Direito, Universidade do Vale do Rio dos Sinos - Unisinos, 2014. [Acesso em 10 jan 2017]. Disponível em:

https://sucupira.capes.gov.br/sucupira/public/consultas/coleta/trabalhoConclusao/viewTrab alhoConclusao.jsf?popup=true\&id_trabalho=1395708.

20. Dworkin, R . Judicial discretion. J Philos, 60(21):624-38, 1963.

21. Dworkin, R . Hard cases. Harvard Law Rev. 1975; 88(6):1057-109.

22. Posner, RA. The problematic of moral and legal theory. 3. ed. Harvard University Press, 2009.

23. Hart, HLA. O conceito de direito. São Paulo: Martins Fontes Editora, 2009.

24. Dworkin, R. Uma questão de princípio. 2. ed. São Paulo: Martins Fontes Editora, 2005.

25. Alexy, R. Teoria da Argumentação Jurídica. 3. ed. Rio de Janeiro: Forense, 2011.

26. Atienza, M. Razões do direito: teorias da argumentação jurídica. 3. ed. São Paulo: Landy, 2003.

\section{Como citar este artigo:}

